\title{
The Use of Nanofibrillar Cellulose Hydrogel As a Flexible Three-Dimensional Model to Culture Human Pluripotent Stem Cells
}

\author{
Yan-Ru Lou, Liisa Kanninen, ${ }^{1}$ Tytti Kuisma, Johanna Niklander, ${ }^{1}$ Luke A. Noon, ${ }^{2}$ \\ Deborah Burks, ${ }^{2}$ Arto Urtti, ${ }^{3}$ and Marjo Yliperttula ${ }^{1}$
}

Human embryonic stem cells and induced pluripotent stem cells have great potential in research and therapies. The current in vitro culture systems for human pluripotent stem cells (hPSCs) do not mimic the threedimensional (3D) in vivo stem cell niche that transiently supports stem cell proliferation and is subject to changes which facilitate subsequent differentiation during development. Here, we demonstrate, for the first time, that a novel plant-derived nanofibrillar cellulose (NFC) hydrogel creates a flexible 3D environment for hPSC culture. The pluripotency of hPSCs cultured in the NFC hydrogel was maintained for 26 days as evidenced by the expression of OCT4, NANOG, and SSEA-4, in vitro embryoid body formation and in vivo teratoma formation. The use of a cellulose enzyme, cellulase, enables easy cell propagation in 3D culture as well as a shift between 3D and two-dimensional cultures. More importantly, the removal of the NFC hydrogel facilitates differentiation while retaining 3D cell organization. Thus, the NFC hydrogel represents a flexible, xeno-free 3D culture system that supports pluripotency and will be useful in hPSC-based drug research and regenerative medicine.

\section{Introduction}

$\mathrm{H}$ UMAN EMBRYONIC STEM CELLS (hESCs) [1] and humaninduced pluripotent stem cells (hiPSCs) [2,3] are capable of self-renewal and differentiation into any cell in the adult human body, and, thus, they hold great promise for cell therapy, drug research, and tissue engineering. For these applications, hESCs and hiPSCs should be expanded, while their spontaneous differentiation should be minimized. Various in vitro culture systems have been developed to provide high-quality human pluripotent stem cells (hPSCs). Conventionally, the cells were cultured on feeder cells [1], and later, the Matrigel coating [4] was introduced to replace the feeder cells in combination with the use of conditioned medium or chemically defined medium, for example, mTeSR1 medium [5]. However, Matrigel includes poorly defined matrix components, which cause poor reproducibility and are also clinically unsuitable. More recently, studies using surfaces coated with vitronectin (VN) [6], laminin-511 (LN-511) [7], synthetic peptide surfaces [8,9], or synthetic polymers [1012] have made good progress in developing chemically defined in vitro culture systems for the propagation of hESCs and hiPSCs at an undifferentiated state. However, all these culture systems are using two-dimensional (2D) surfaces that do not mimic the in vivo environment of stem cells, which is called a stem cell niche. The niche is a well-defined, complex three-dimensional (3D) microenvironment in which the cells of the inner cell mass of the blastocyst form 3D cellular associations [13]. Moreover, stem cells cultured on 2D surfaces cannot readily differentiate toward 3D functional tissue-like structures that are required for therapy and research.

To create a 3D stem cell niche, various cross-linked 3D hydrogels and scaffolds have been used to produce hPSC spheroids or aggregates [14-17]. The cell spheroids and aggregates are formed in an environment with fixed physicochemical cues (eg, gelified alginate [15,17], polymerized hyaluronic acid [14], and polymer scaffold [16]) that are suitable only for stem cells and cannot be tuned during the culture to support differentiation processes in a variety of biomedical applications. To induce directed differentiation, the 3D stem cell-biomaterial organization should be destroyed, and the stem cells are transferred to a new system that is optimal for differentiation. This design is different from the natural stem cell niche in the blastocyst, which transiently supports stem cell proliferation and is subject to changes to facilitate subsequent differentiation during development. This concept has not yet been realized. A dynamic, flexible 3D in vitro culture system is still lacking.

\footnotetext{
${ }^{1}$ Division of Biopharmaceutics and Pharmacokinetics, Faculty of Pharmacy, University of Helsinki, Helsinki, Finland.

${ }^{2}$ Laboratorio de Neuroendocrinología Molecular, Principe Felipe Centro de Investigacion, Valencia, Spain.

${ }^{3}$ Faculty of Pharmacy, Centre for Drug Research, University of Helsinki, Helsinki, Finland.
} 
Another approach to producing hPSCs aggregates or clusters is to use soluble factors instead of biomaterials in a suspension culture [18-21]. However, karyotypic abnormalities were observed in some cell lines in the suspension culture [20]. Frequent dissociation of aggregates into single cells is needed, as the large aggregates develop necrosis in the center [21]. It is worth noting that the suspension culture does not provide a 3D environment for subsequent 3D differentiation.

We recently showed that a novel nanofibrillar cellulose (NFC) hydrogel promotes the functional 3D spheroid formation of human liver cells [22]. NFC is a plant-derived material with fiber diameter in nanometer range and fiber length in micrometer range. These fibrils are composed of aligned $\beta_{-}^{-}{ }^{-}(1 \rightarrow 4)$ glucopyranose polysaccharide chains [23]. NFC can be isolated from the cell walls of wood and plants. They form hydrogels with tuneable physical and chemical properties [24,25] and are shown to be non-cytotoxic [26]. Therefore, they have diverse pharmaceutical and biomedical applications [27-29]. When used in cell culture, the NFC hydrogel is mixed with cells without any polymerization process.

In this study, we demonstrate, for the first time, that the NFC hydrogel creates a flexible 3D environment for proliferation and differentiation of hPSCs.

\section{Materials and Methods}

\section{Generation of H9-GFP}

H9-GFP cells (clone 24) were prepared by clonal selection of H9 cells (also known as WiCell WA09; WiCell) that were lentivirally transducted with rLV-EF1-GFP (Vectalys). Before infection, cells were disaggregated to single cells using accutase and plated in Corning non-adherent plates in hESC medium. After a 2-h transduction using a multiplicity of infection of 50, cells were washed, resuspended in fresh medium, and seeded onto STO feeders. GFP-positive colonies arising from single cells were identified by fluorescence microscopy and isolated mechanically for passaging.

\section{Cell culture on the standard Matrigel platform and in the NFC hydrogel}

H9 (WA09) and WA07 [1] are hESC lines. iPS(IMR90)-4 [3] is a hiPSC line. WA07 and iPS(IMR90)-4 were purchased from WiCell. H9-GFP cell line was modified from H9 cell line that had been originally from WiCell. The cells were maintained on Matrigel-coated dishes in mTeSR1 medium (STEMCELL Technologies) at $37^{\circ} \mathrm{C}$ in a humid atmosphere with $5 \% \mathrm{CO}_{2}$. Matrigel coating was prepared by incubating Matrigel (Matrigel ${ }^{\mathrm{TM}}$ basement membrane matrix growth factor reduced from BD Biosciences) dilution ( $0.5 \mathrm{mg}$ per one 6-well plate) in tissue-culture plates at room temperature for $1 \mathrm{~h}$ as described in the WiCell stem cell protocol. The medium was renewed daily, and the cells were passaged at a ratio of $1: 4$ to $1: 10$ every $4-5$ days using either $1 \mathrm{mg} / \mathrm{mL}$ dispase solution (STEMCELL Technologies) or Versene 1:5,000 (Invitrogen) for $7 \mathrm{~min}$. The differentiated cells were removed by a pipette before splitting.

The colony density of hESCs and hiPSCs in $0.5 \mathrm{wt} . \%$ NFC hydrogel was five times higher than that of the culture in the
Matrigel platform before passaging. 1.8wt.\% of NFC hydrogel stock solution (GrowDex ${ }^{\mathrm{TM}}$; UPM-Kymmene Corporation) was prepared from bleached birch pulp without any additional chemical modification. The NFC hydrogel is a mixture of cellulose and hemicellulose macromolecules and pure water. The hemicellulose fraction is mainly xylene, which generates slightly anionic surface charge $(-2 \mathrm{mV})$ on the fibrillar structures. The overall carbohydrate composition is as follows: $72.8 \%$ Glucose, $25.6 \%$ Xylose, and 1.4\% Mannose. The nanofibers are mainly composed of cellulose macromolecules, corresponding to the glucose fraction, and hemicellylose xylene is forming dangling chains on the fibrillar surfaces. $1.8 \mathrm{wt}$.\% of NFC hydrogel stock solution was diluted in mTeSR1 medium and mixed with stem cell colonies. The same amount of mTeSR1 medium was added on top of cell-hydrogel mixture. The medium was renewed daily.

\section{Subculture of hPSCs in the NFC hydrogel and recovery of $3 D$ spheroids to $2 D$ platforms}

The cells cultured in the NFC hydrogel were passaged every 7-12 days to new NFC hydrogel or to 2D platforms. Cellulase (VTT) was used to subculture the 3D hPSCs and to recover spheroids from the hydrogel to 2D platforms. The optimal working temperature of cellulase is $45-50^{\circ} \mathrm{C}$, which is, however, not suitable for human cells. The incubation time with cellulase should be extended to $24 \mathrm{~h}$ at $37^{\circ} \mathrm{C}$. Before cellulase treatment, the old mTeSR 1 medium was removed, and cellulase diluted in mTeSR1 medium was added and incubated with cell-hydrogel mixture at $37^{\circ} \mathrm{C}$ for $24 \mathrm{~h}$.

After the enzymatic removal of NFC, hPSC spheroids were collected and treated with Versene 1:5,000 for $7 \mathrm{~min}$ at room temperature. The smaller colonies were generated by passing them through $1,000 \mu \mathrm{L}$ pipette tip for $\sim 10$ times. For 3D subculture, the smaller cell colonies were mixed with 0.5 wt. $\%$ NFC hydrogel as described earlier. To transfer colonies to 2D platforms, the smaller cell colonies were seeded on four different coatings: Matrigel, VN (R\&D Systems), LN-511, and LN-521 (BioLamina) with a splitting ratio of 1:8 to $1: 9$. Matrigel coating was prepared as usual. LN-511 and LN-521 coatings were prepared by following the manufacturer's instructions. Briefly, $20 \mu \mathrm{g} / \mathrm{mL}$ LN-511 or $20 \mu \mathrm{g} / \mathrm{mL} \mathrm{LN}-521$ was incubated in tissue-culture plates at $37^{\circ} \mathrm{C}$ for $2 \mathrm{~h}$ and then at $4^{\circ} \mathrm{C}$ overnight. VN coating was prepared by incubating $5 \mu \mathrm{g} / \mathrm{mL} \mathrm{VN}$ at $4^{\circ} \mathrm{C}$ overnight as previously described [6].

\section{Mitochondrial metabolic activity}

AlamarBlue $^{\circledR}$ reagent (Invitrogen) was used to measure the mitochondrial metabolic activity of hPSCs before and after cellulase treatment in order to select a nontoxic enzyme concentration. Before and after treatment with various concentrations of cellulose, 2.5\% AlamarBlue reagent was added into mTeSR1 medium and incubated with cells at $37^{\circ} \mathrm{C}$ for $24 \mathrm{~h}$. The fluorescence of the AlamarBlue metabolite was measured at an excitation wavelength of $570 \mathrm{~nm}$ and an emission wavelength of $585 \mathrm{~nm}$ by a Varioskan Flash spectral scanning multimode reader 2.4.2 (Thermo Scientific). 


\section{NFC staining and live cell imaging using a confocal microscope}

To evaluate the enzymatic removal of NFC, calcofluor white stain (Sigma FLUKA) was added into the culture to stain cellulose following the manufacturer's instructions. GFP fluorescence of the live H9-GFP cells and stained NFC were visualized under a Leica TCS SP5II HCS A confocal microscope using Argon $488 \mathrm{~nm}$ and UV $405 \mathrm{~nm}$ lasers, respectively, at $37^{\circ} \mathrm{C}$ with $5 \% \mathrm{CO}_{2}$. Live/dead viability/cytotoxicity kit (Invitrogen) was used to assess cell viability in the spheroids.

\section{Immunofluorescence and immunohistochemistry}

hPSCs cultured either on different 2D platforms or in the NFC hydrogel were fixed in $3.7 \%$ paraformaldehyde for $10 \mathrm{~min}(2 \mathrm{D})$ or $30 \mathrm{~min}(3 \mathrm{D})$ at room temperature followed by permeabilization with $0.1 \%$ Triton $\mathrm{X}-100$ or $0.5 \%$ saponin for $10 \mathrm{~min}(2 \mathrm{D})$ or $30 \mathrm{~min}$ (3D). After blocking with $10 \%$ normal goat or donkey sera (Millipore), cells were incubated with anti-Oct-3/4 (Santa Cruz Biotechnology; sc-9081, 1:500), antiSSEA-4 (Developmental Studies Hybridoma Bank; MC-813-70, 1:100), anti- $\beta$-tubulin isotype III (Sigma; T5076, 1:2,000), antiAFP (Sigma; A8452, 1:500), anti-muscle actin (Dako; IS70030), or anti-HNF3B (Santa Cruz Biotechnology; sc-6554, 1:50) at $4^{\circ} \mathrm{C}$ overnight. Negative control samples incubated with control rabbit immunoglobulin $\mathrm{G}$ (IgG), mouse IgG, or goat IgG (Santa Cruz Biotechnology) were prepared in parallel. The secondary antibody, which was goat-anti-rabbit Alexa Fluor 594, goat-anti-mouse Alexa Fluor 594, or donkeyanti-goat Alexa Fluor 594 (Invitrogen) at a dilution of 1:400, was used at room temperature for $1 \mathrm{~h}(2 \mathrm{D})$ or $6 \mathrm{~h}(3 \mathrm{D})$. All washings using phosphate-buffered saline- $0.2 \%$ Tween 20 were repeated thrice, $5 \mathrm{~min}$ each. After immunostaining, nuclei were stained with SYTOX Green (Invitrogen). Cells were then mounted with VECTASHIELD mounting medium (Vector Laboratories). The staining was viewed under a Leica TCS SP5II HCS A confocal microscope using Argon $488 \mathrm{~nm}$ laser for GFP and SYTOX Green and DPSS $561 \mathrm{~nm}$ laser for Alexa Fluor 594. The confocal images were analyzed with Imaris 7.4 software (Bitplane AG).

In some experiments, hPSC spheroids and embryoid bodies (EBs) were fixed in 3.7\% paraformaldehyde and embedded in HistoGel (Thermo Scientific). Subsequently, the standard paraffin embedding and sectioning were per- formed at the Finnish Center for Laboratory Animal Pathology. Five-micrometer-thick sections were used in immunohistochemistry.

\section{RNA extraction and real-time quantitative reverse transcription-polymerase chain reaction}

Total RNA was extracted using RNeasy Mini (RNA from cultured cells) and RNeasy Midi kit (RNA from teratoma) (Qiagen) following the manufacturer's instructions. RNA samples were quantified using a NanoDrop 2000 spectrophotometer (Thermo Fisher Scientific). All the RNA samples were converted into cDNA at the same experiment to ensure the same reverse transcription efficiency. The cDNA synthesis was performed by using a High-Capacity RNAto-cDNA kit (Applied Biosystems). All the cDNA samples were analyzed in duplicate using a Fast SYBR Green Master Mix (Applied Biosystems) on a StepOnePlus RealTime PCR System (Applied Biosystems). For each gene, a standard curve was generated, and amplification efficiency was taken into account in calculations. Polymerase chain reaction (PCR) product quality was monitored using postPCR melt curve analysis. All primers were synthesized by Oligomer Oy. The housekeeping gene RPLPO was used as an endogenous control. The PCR cycling conditions were as follows: 40 cycles of $3 \mathrm{~s}$ at $95^{\circ} \mathrm{C}$ and $30 \mathrm{~s}$ annealing/ extension at $60^{\circ} \mathrm{C}$. The primer sequences were shown in Table 1.

\section{In vitro differentiation via $E B$ formation}

iPS(IMR90)- 4 cells were cultured in $0.5 \%$ NFC hydrogel for 8 days and then treated with cellulase for $24 \mathrm{~h}$. The EB medium consisting of Iscove's modified Dulbecco's medium (Invitrogen) supplemented with 15\% HyCloneDefined fetal bovine serum (Thermo Scientific) was used in the EB formation. To form EBs, two methods were used. In a direct method, the cell spheroids that recovered from the hydrogel were directly cultured in suspension in the EB medium in Nunc HydroCell surface $3.5 \mathrm{~cm}$ dishes (NUNC) for 4 weeks. In an indirect method, cells were first recovered from the hydrogel and then cultured in mTeSR 1 medium in Matrigel-coated dishes for 4 days. The 2D cell colonies were then used to form EBs in suspension in the EB medium for 4 weeks. To form EBs from 2D culture, the WiCell protocol was followed. In brief, cell colonies were detached from

Table 1. Primer Sets for Real-Time Quantitative Polymerase Chain Reaction

\begin{tabular}{|c|c|c|c|}
\hline Genes & Accession & Size $(b p)$ & Sequences ( $5^{\prime}$ to $\left.3^{\prime}\right)$ \\
\hline \multirow[t]{2}{*}{ RPLPO } & NM_053275.3 & 74 & F: AATCTCCAGGGGCACCATT \\
\hline & & & R: CGCTGGCTCCCACTTTGT \\
\hline \multirow[t]{2}{*}{ OCT4 } & NM_002701.4 & 161 & F: CAGTGCCCGAAACCCACAC \\
\hline & & & R: GGAGACCCAGCAGCCTCAAA \\
\hline \multirow[t]{2}{*}{ NANOG } & NM_024865.2 & 80 & F: GCAGAAGGCCTCAGCACCTA \\
\hline & & & R: GGTTCCCAGTCGGGTTCAC \\
\hline \multirow[t]{2}{*}{ PAX6 } & NM_001604.5 & 126 & F: GCCCTGGAGAAAGAGTTTGAGA \\
\hline & & & R: CCATTTGGCCCTTCGATTAGA \\
\hline \multirow[t]{2}{*}{$C D X 2$} & NM_001265.4 & 168 & F: GGCAGCCAAGTGAAAACCA \\
\hline & & & R: CCAGATTTTAACCTGCCTCTCA \\
\hline \multirow[t]{2}{*}{ BRACHYURY } & NM_003181.3 & 118 & F: AGAACGGCAGGAGGATGTTTCC \\
\hline & & & R: ACGTACTTCCAGCGGTGGTTGT \\
\hline
\end{tabular}


Matrigel-coated wells by $1 \mathrm{mg} / \mathrm{mL}$ dispase for $17 \mathrm{~min}$ at $37^{\circ} \mathrm{C}$. Small colonies and debris were removed by a $100 \mu \mathrm{m}$ cell strainer (BD Biosciences). The remaining colonies were cultured in the EB medium in Nunc HydroCell surface $3.5 \mathrm{~cm}$ dishes for 4 weeks.

At every week, EBs were collected and dissociated using Versene 1:5,000. The resulting cells were seeded on Lab-Tek eight-well chamber slides (NUNC) that were coated with ESqualified $0.1 \%$ gelatin (Millipore) in the EB medium for an additional week of culture. The cells were then fixed in $3.7 \%$ paraformaldehyde for $10 \mathrm{~min}$ at room temperature and detected by immunofluorescence. In addition, at every week, EBs were collected, fixed in $3.7 \%$ paraformaldehyde for $30 \mathrm{~min}$ at room temperature, and embedded in HistoGel (Thermo Scientific). Immunohistochemistry was performed as described in the earlier section.

\section{Teratoma formation}

After a 26-day culture of WA07 cells in $0.5 \mathrm{wt} \% \%$ NFC hydrogel, the cell spheroids were harvested after cellulase treatment, collected into tubes, and pelleted by centrifugation. Teratoma assays were performed by injecting the spheroids into the testis of two nude NMRI mice at the Biomedicum Helsinki Stem Cell Center. The tumors were harvested at 6 weeks after the injection, fixed in $4 \%$ paraformaldehyde, and processed for paraffin embedding. Hematoxylin- and eosin-stained sections $(5 \mu \mathrm{m})$ were morphologically analyzed for the presence of derivatives of all germ layers. Parts of the fresh tumors were stored in RNAlater RNA stabilization reagent (Qiagen) for subsequent RNA isolation and real-time quantitative reverse transcriptionpolymerase chain reaction (RT-PCR).

A

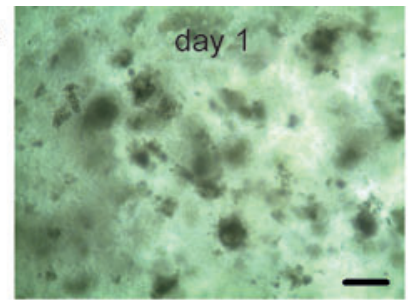

B
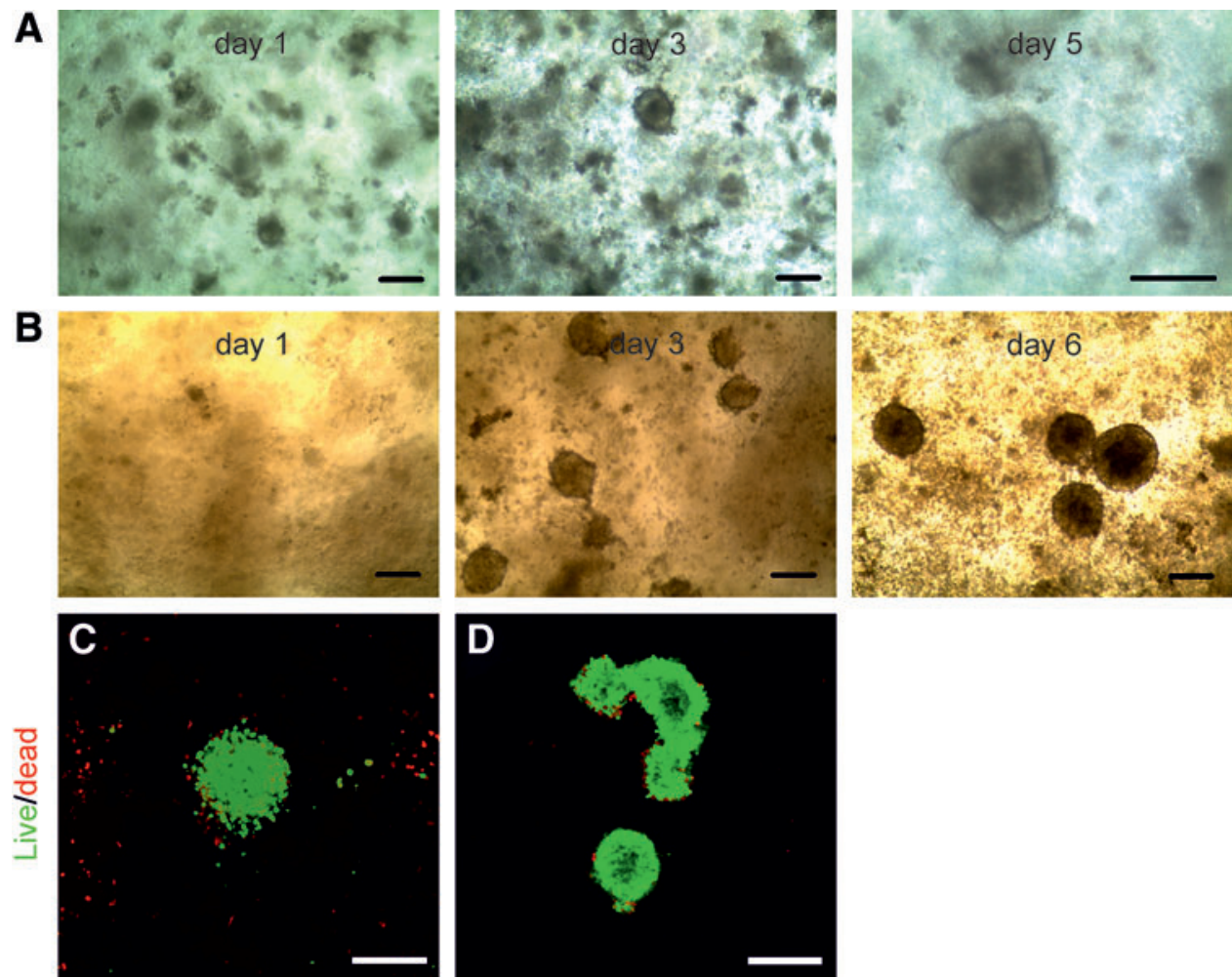

\section{Karyotyping}

For karyotyping analyses, WA07 and iPS(IMR90)-4 cell spheroids were recovered from the hydrogel and seeded to Matrigel-coated dishes following the procedure mentioned earlier. Chromosomal G-band analyses were performed at the United Medix laboratories Ltd.

\section{Statistical analysis}

Statistical significance was determined by one-way analysis of variance followed by Holm-Sidak post-test (SigmaPlot). Differences of $P>0.05$ were not considered significant, and $\left.P<0.01{ }^{* *}\right)$ and $P<0.001\left(^{* * *}\right)$ were considered significant (Figs. 2 and 4).

\section{Results}

\section{Formation of $3 D$ hPSC spheroids in the NFC hydrogel}

In this study, we explored the possibility of creating 3D hPSC spheroids in a flexible environment that enables further differentiation without disrupting 3D stem cell organization. We cultured hPSCs in a novel NFC hydrogel and generated 3D spheroids. The NFC hydrogel concentration affects 3D spheroid formation. hPSCs failed to form spheroids in 1 wt.\% NFC hydrogel (Supplementary Fig. S1; Supplementary Data are available online at www.liebertpub .com/scd), but hPSCs developed 3D spheroids with diameters between 100 and $250 \mu \mathrm{m}$ in $0.5 \mathrm{wt}$.\% NFC hydrogel (Fig. 1A, B; Supplementary Fig. S1). Phase-contrast images show that cell density and spheroid diameter increased with culture time (Fig. 1A, B). The cells in 3D spheroids remained
FIG. 1. Human embryonic stem cells (ESCs) and induced pluripotent stem cells (iPSCs) form three-dimensional (3D) spheroids in the nanofibrillar cellulose (NFC) hydrogel. (A, B) A time course shows that WA07 (A) and iPS(IMR90)-4 (B) cells formed 3D spheroids in 0.5 wt.\% NFC hydrogel. (C, D) Live/dead staining images show living WA07 (C) and iPS(IMR90)-4 (D) cells in the spheroids on day 9. Scale bars $=200 \mu \mathrm{m}$. Color images available online at www.liebertpub.com/scd 
A

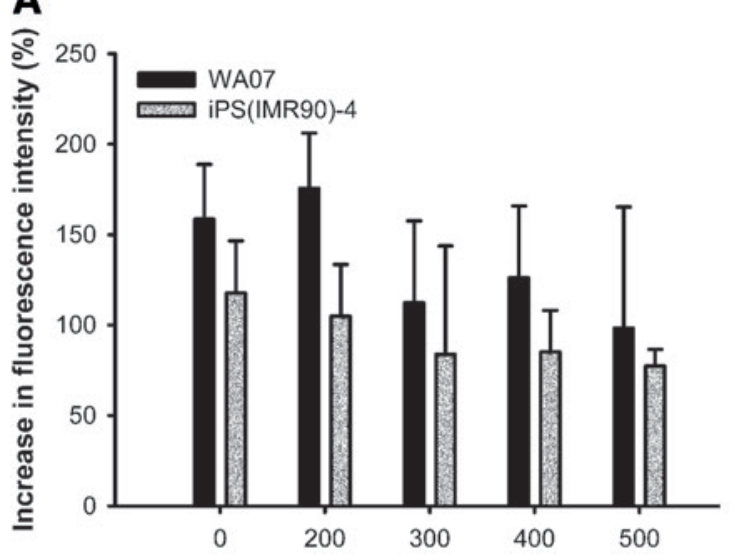

Cellulase concentration $(\mu \mathrm{g} / \mathrm{mg}$ cellulose)

C
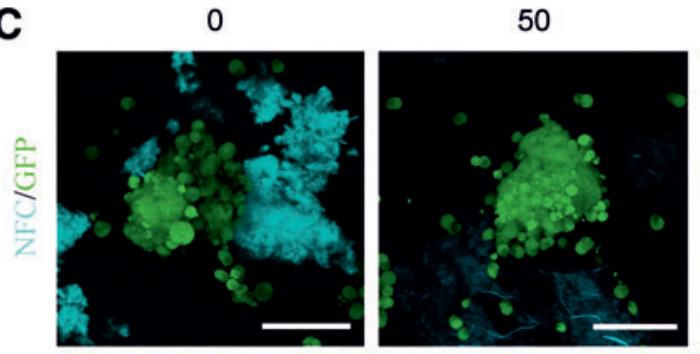

D
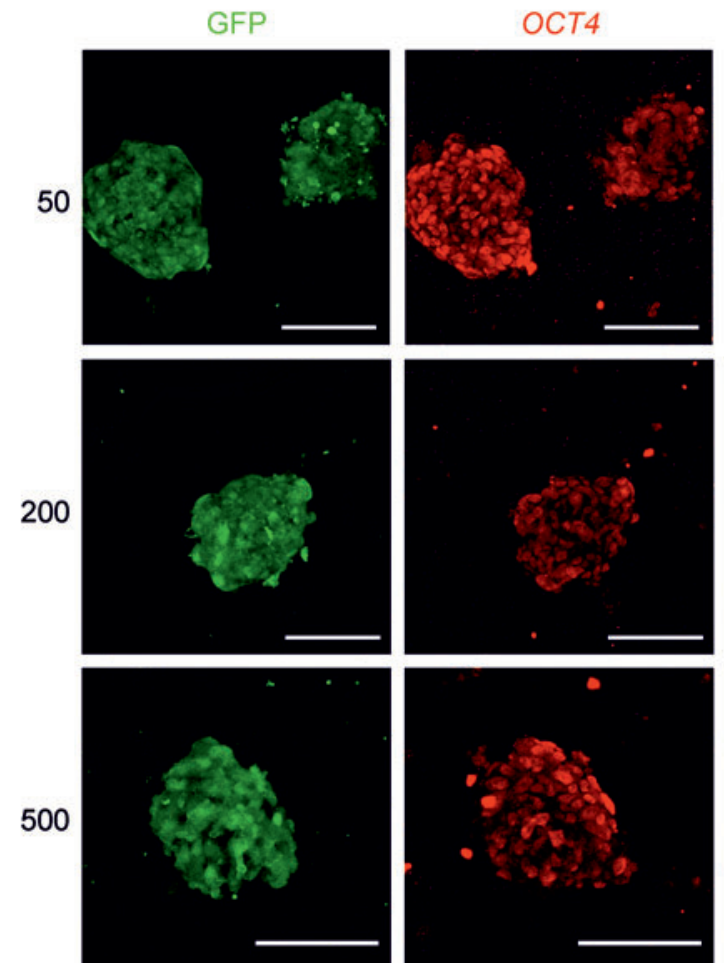

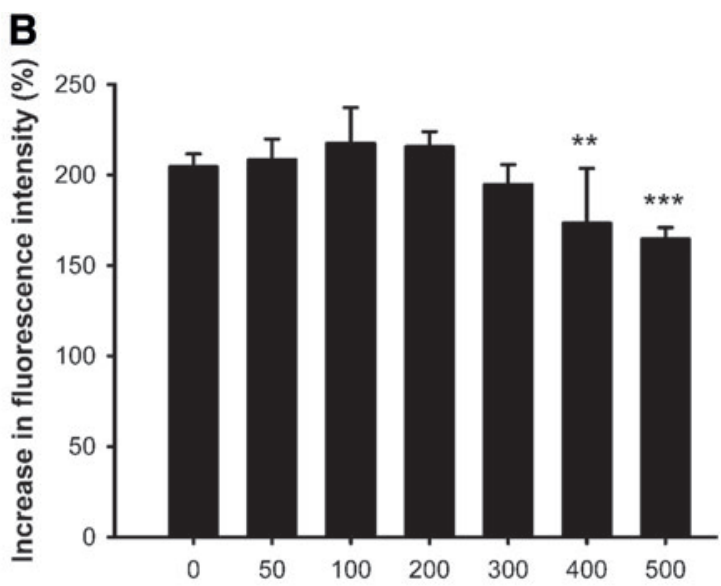

Cellulase concentration $(\mu \mathrm{g} / \mathrm{mg}$ cellulose)

200

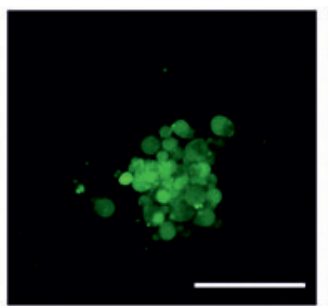

Merge
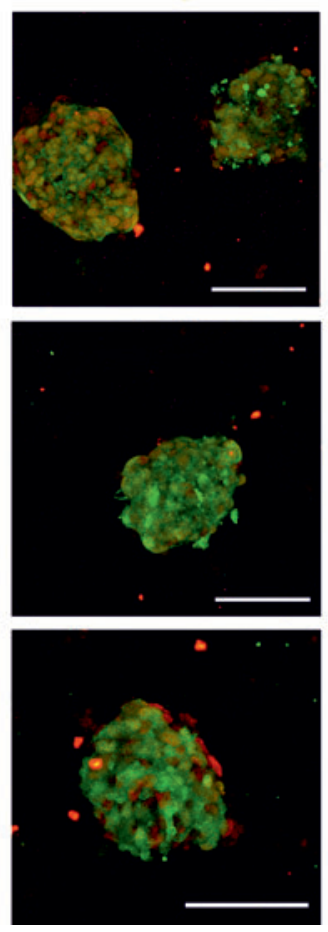

FIG. 2. Enzymatic removal of the NFC hydrogel. (A, B) Mitochondrial metabolic activity of WA07 and iPS(IMR90)-4 cells (A) and H9-GFP cells (B) as a function of the concentration of cellulase. Cells cultured on a standard Matrigel platform were treated with cellulase at various concentrations ( $\mu \mathrm{g}$ cellulase $/ \mathrm{mg}$ cellulose). The mitochondrial metabolic activity was determined by an AlamarBlue ${ }^{\circledR}$ assay, and the increase in fluorescence intensity after a 24-h treatment with cellulase is presented. Four (A) or six (B) biological samples for each condition were prepared. The results are expressed as mean \pm standard deviation (SD). (C) Removal of cellulose by $0,50,200$, and $500 \mu \mathrm{g}$ cellulase/mg cellulose is visualized by calcofluor white staining of cellulose, which is represented in blue. H9-GFP cells are seen in green. (D) A pluripotency marker OCT4 is expressed in H9-GFP cells that are cultured in $0.5 \mathrm{wt} . \%$ NFC hydrogel after treatment with cellulase at 50, 200, and $500 \mu \mathrm{g} / \mathrm{mg}$ cellulose. Scale bars $=100 \mu \mathrm{m} .{ }^{* *} P<0.01$ and ${ }^{* * *} P<0.001$. Color images available online at www.liebertpub.com/scd 

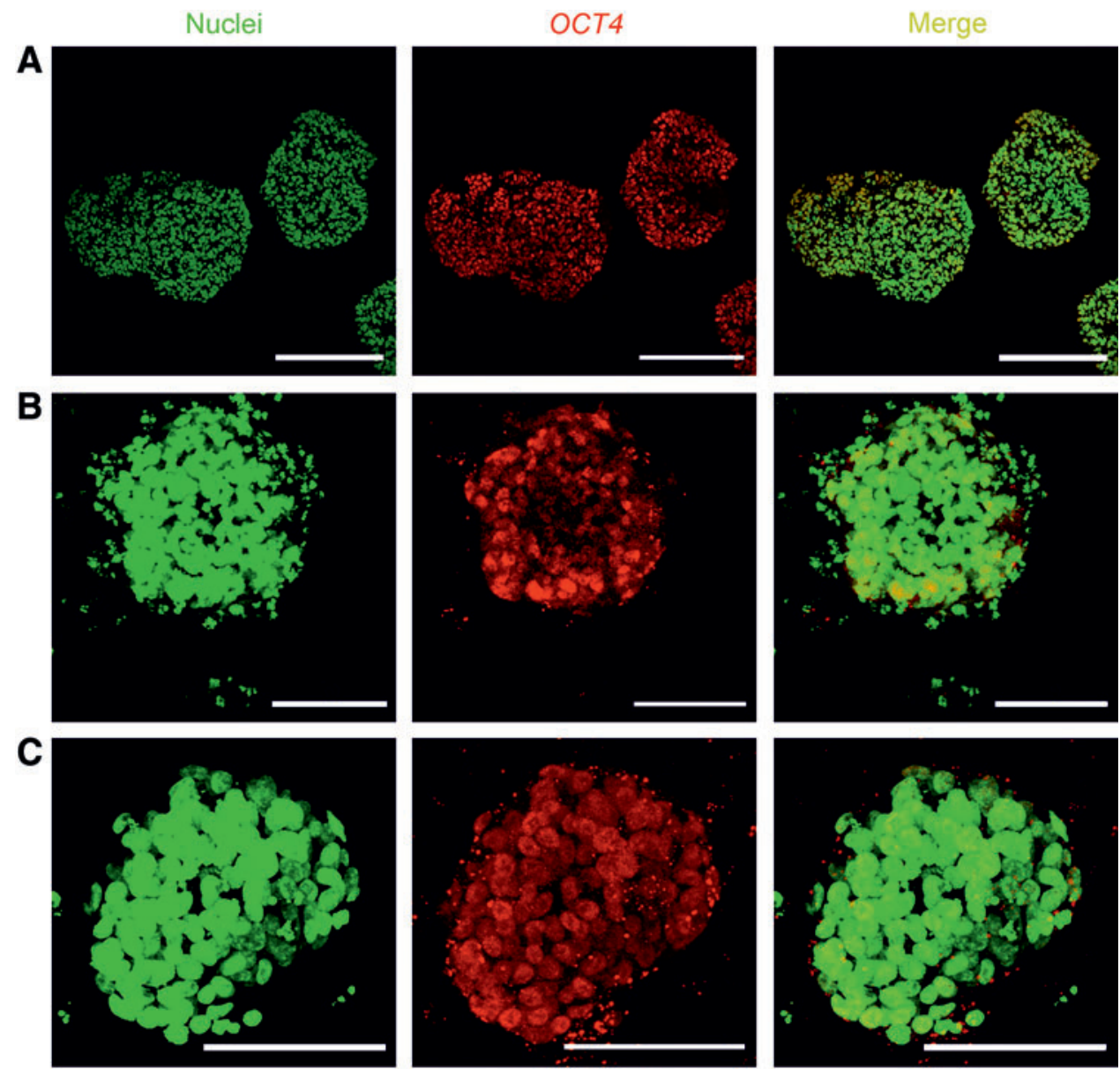

FIG. 3. OCT4 expression in the 3D human pluripotent stem cell (hPSC) spheroids. The pluripotency marker OCT4 is expressed in WA07 cells that are cultured in $0.5 \%$ NFC hydrogel for 7 days [(A), $5 \mu \mathrm{m}$ paraffin section], for 9 days (B), for 16 days after one subculture (C), and for 26 days after three subcultures [(D), $5 \mu \mathrm{m}$ paraffin section]. OCT4 is also expressed in iPS(IMR90)-4 cells that are cultured in $0.5 \mathrm{wt}$ \% NFC hydrogel for 9 days (E). Scale

D

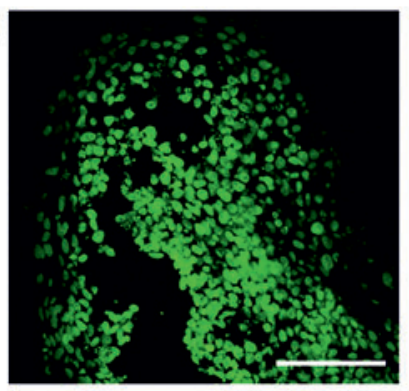

E

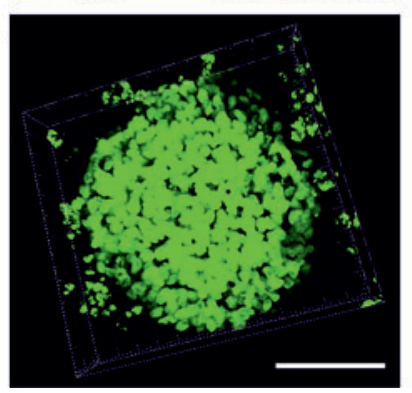

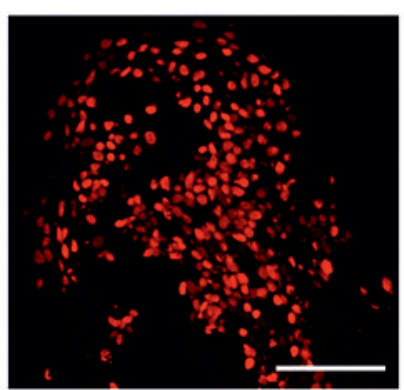

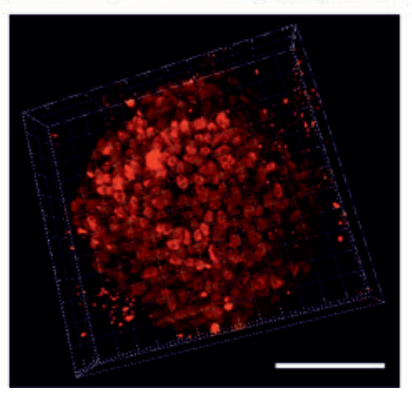

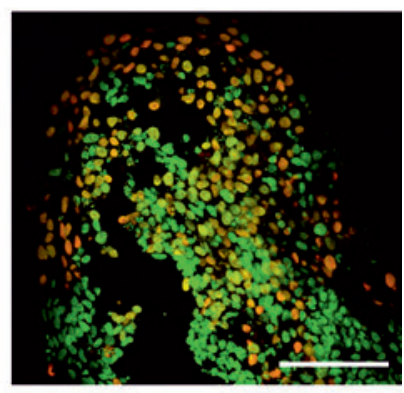

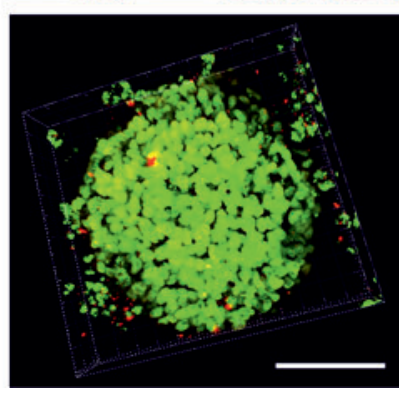
bars $=200 \mu \mathrm{m}$ (A) and $100 \mu \mathrm{m}$ (B-E). Color images available online at www.liebertpub .com/scd alive during the culture as shown in live/dead viability assays at the end of subcultures (Fig. 1C, D).

\section{Enzymatic removal of the NFC hydrogel}

We made use of cellulase to subculture 3D hPSCs and to recover spheroids from the hydrogel to $2 \mathrm{D}$ platforms. Cel- lulase is an enzyme that specifically degrades cellulose without affecting animal cells, because animal cells do not contain cellulose $[30,31]$. The degraded products of the NFC are nontoxic sugars. Before using cellulase in the 3D culture, we optimized cellulase concentration in a standard Matrigel platform for each hPSC line. AlamarBlue assay was used to assess cell viability and the possible toxicity of cellulase. 
Figure $2 \mathrm{~A}$ and $\mathrm{B}$ show that cellulase at concentrations no more than $300 \mu \mathrm{g} / \mathrm{mg}$ cellulose had no statistically significant effect on the viability and growth of WA07, iPS(IMR90)4, and H9-GFP cells. The removal of cellulose was visualized by calcofluor white stain, which is a cellulose-binding fluorochrome. The use of H9-GFP cells enabled us to monitor the spheroid structure after the enzymatic removal of the NFC hydrogel. The 3D spheroids stayed intact after the treatment with cellulase at 50, 200, and $500 \mu \mathrm{g} / \mathrm{mg}$ cellulose, and cellulase below $200 \mu \mathrm{g} / \mathrm{mg}$ cellulose was insufficient to remove NFC (Fig. 2C). OCT4 was immunodetected in H9-GFP cell spheroids after the enzymatic removal of the NFC hydrogel (Fig. 2D).

\section{Pluripotency of hPSCs cultured in the NFC hydrogel}

To determine whether hPSCs cultured in the NFC hydrogel are pluripotent, we performed extensive analyses, including pluripotency marker expression, in vitro EBmediated differentiation, and teratoma assay. WA07 (Fig. 3AD) and iPS(IMR90)-4 (Fig. 3E) cells in 3D spheroids during 26-day culture expressed the pluripotency marker OCT4 shown by immunofluorescence. In contrast, iPS(IMR90)-4 (Supplementary Fig. S2A) and WA07 (Supplementary Fig. S2B, C) cells did not express the differentiation markers $\beta$ tubulin type III, HNF3B, and muscle actin. Real-time quantitative RT-PCR shows that during a 26-day culture in the hydrogel, WA07 cells in the spheroids expressed a similar amount of NANOG mRNA as cells cultured on the standard Matrigel platform ( $\mathrm{M}$ ctrl) (Fig. 4B). The expression of OCT4 mRNA in WA07 spheroids was maintained at day 7 but dropped by $\sim 50 \%$ at day $26(P<0.001$, Fig. 4 A). A possible explanation is that the manual removal of spontaneous differentiation was not performed in the 3D culture, whereas it is a routine procedure before every subculture on the standard Matrigel platform.

The 3D culture can be easily shifted to various 2D platforms. We used four 2D platforms, namely Matrigel coating, LN-511 coating, LN-521 coating, and VN coating. By using $300 \mu \mathrm{g}$ cellulase $/ \mathrm{mg}$ cellulose at $37^{\circ} \mathrm{C}$ for $24 \mathrm{~h}$, we were able to recover the intact spheroids. WA07 cells from the recovered spheroids possessed the characteristics of undifferentiated hESCs when they were plated to the Matrigel, LN-511, LN-521, and VN coatings (Fig. 5A-D). They also expressed OCT4 and SSEA-4 proteins as shown by immunofluorescence (Fig. 5A-D). We obtained the same results using iPS (IMR90)-4 (Fig. 6) and H9-GFP (Supplementary Fig. S3) cells. The differentiation markers $\beta$-tubulin type III, $H N F 3 B$, and muscle actin were not detected in WA07 cells (Supplementary Fig. S4) and iPS(IMR90)-4 cells (Supplementary Fig. S5). After being cultured in the NFC hydrogel, WA07 cells maintained the expression of OCT4 and NANOG mRNA on the Matrigel, LN-511, LN-521, and VN coatings (Fig. 4). iPS(IMR90)-4 cells maintained the expression of NANOG mRNA (Fig. 4B) but showed a reduction in OCT4 mRNA expression when cultured in LN-511, LN-521, and VN (Fig. $4 \mathrm{~A})$. When comparing the four 2D platforms, we noticed that Matrigel coating was the best to maintain high levels of NANOG and OCT4 mRNA expression (Fig. 4).

We demonstrate that after being cultured in the NFC hydrogel, iPS(IMR90)-4 cells were able to differentiate into three germ layers as shown by immunostaining of $\beta$-tubulin
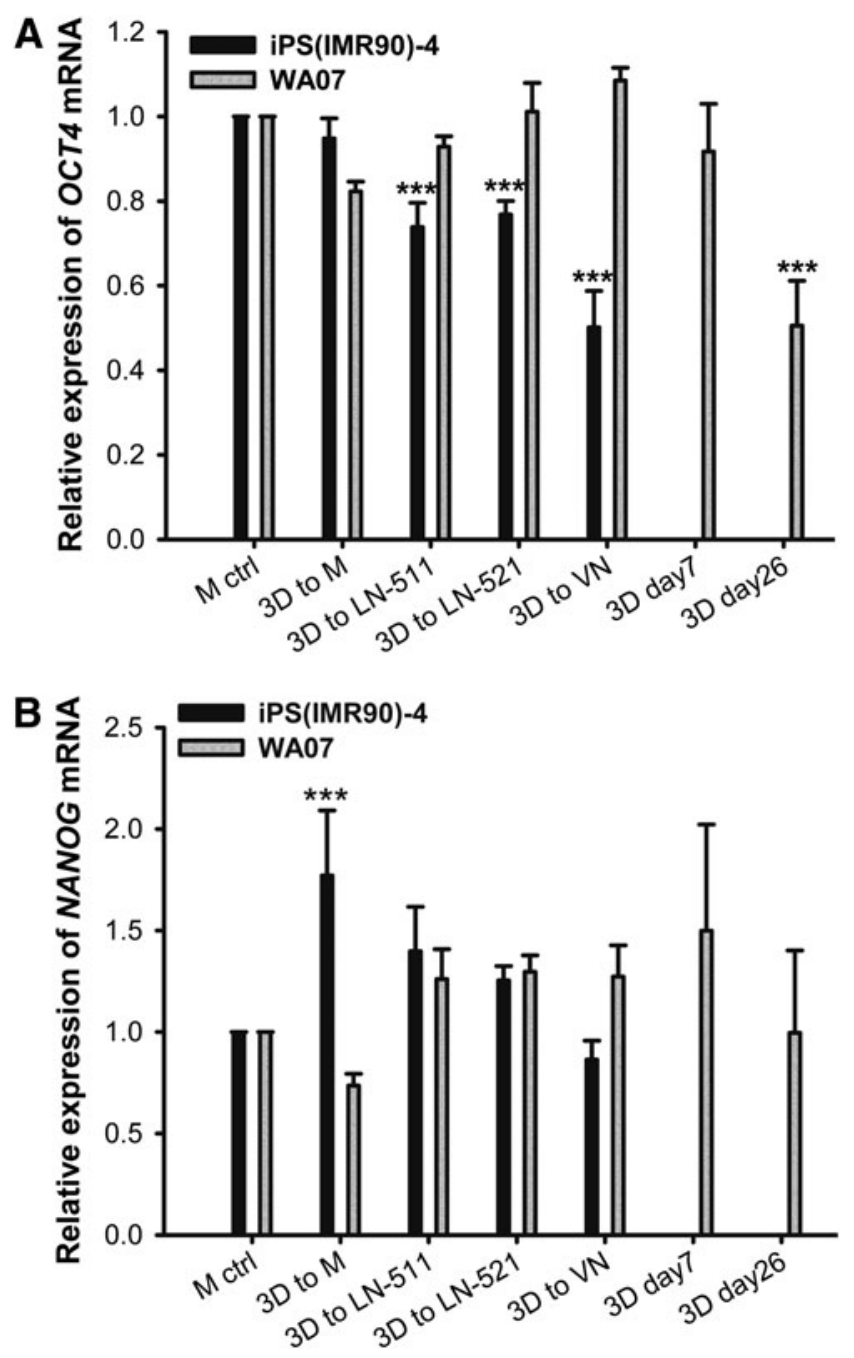

FIG. 4. Gene expression in hPSCs cultured in 3D and twodimensional (2D) platforms. Real-time quantitative reverse transcription-polymerase chain reaction (RT-PCR) analyses of OCT4 (A) and NANOG (B) mRNA expression in WA07 cells cultured in the NFC hydrogel for 9 days and iPS(IMR90)-4 cells cultured in the hydrogel for 12 days and then transferred to $2 \mathrm{D}$ platforms [3D to M, 3D to laminin-511 (LN-511), 3D to LN-521, and 3D to vitronectin (VN)] as well as WA07 cells in 3D spheroids at days 7 (3D day 7) and 26 (3D day 26). Relative mRNA expression was normalized to the control gene RPLP0, and fold inductions were calculated with reference to the cells cultured on the standard Matrigel platform (M ctrl). $n=3$ biological samples. Error bars are SD. ${ }^{* * *} P<0.001$.

type III, muscle actin, and AFP (Fig. 7A) and real-time quantitative RT-PCR analyses of $P A X 6, C D X 2$, and $B R A$ CHYURY (Fig. 7B). The EBs derived from iPS(IMR90)-4 cells exhibited tightly packed morphology (dark EBs) during the first week of EB culture (Supplementary Fig. S6A). The other types of EBs, such as bright EBs and cystic EBs, appeared after a 1-week culture (Supplementary Fig. S6B). iPS(IMR90)4 cells also differentiated into pigmented cells (Supplementary Fig. S6C) and developed beating "hearts" in the third week of EB culture (Supplementary Video S1). The EBmediated differentiation potency of iPS(IMR90)-4 cells did not differ between EBs formed directly from 3D spheroids 


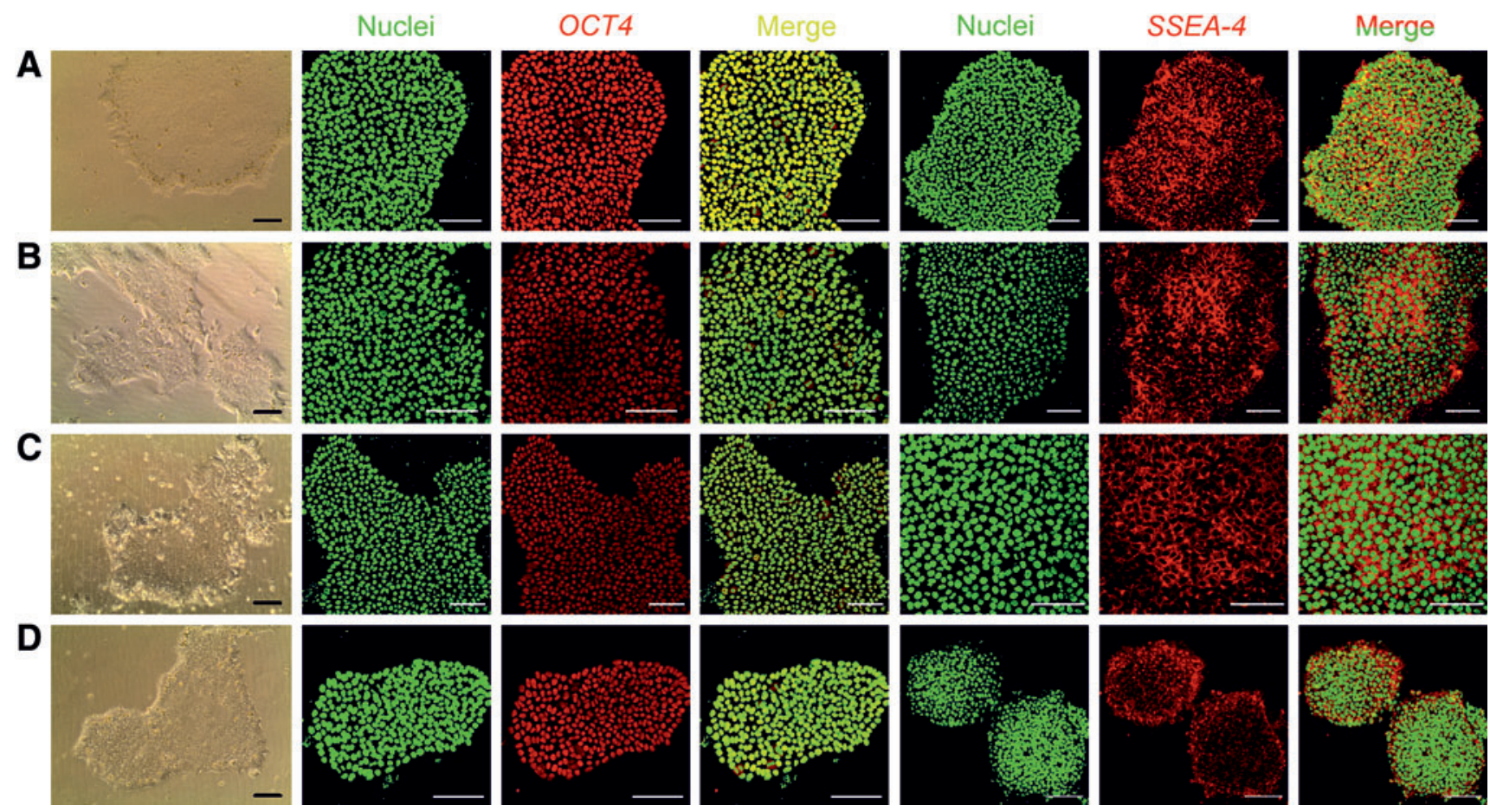

FIG. 5. Transfer of WA07 3D spheroids to 2D platforms. (A-D) WA07 cells were first cultured in 0.5 wt. $\%$ NFC hydrogel for 9 days and then transferred to 2D platforms after a 24-h-treatment with $300 \mu \mathrm{g}$ cellulase $/ \mathrm{mg}$ cellulose at $37^{\circ} \mathrm{C}$. The cells exhibited typical hPSC morphology and expressed the pluripotency markers OCT4 and SSEA-4 on Matrigel-coated dishes (A), LN-511-coated dishes (B), LN-521-coated dishes (C), and VN-coated dishes (D). Scale bars $=100 \mu \mathrm{m}$. Color images available online at www.liebertpub.com/scd

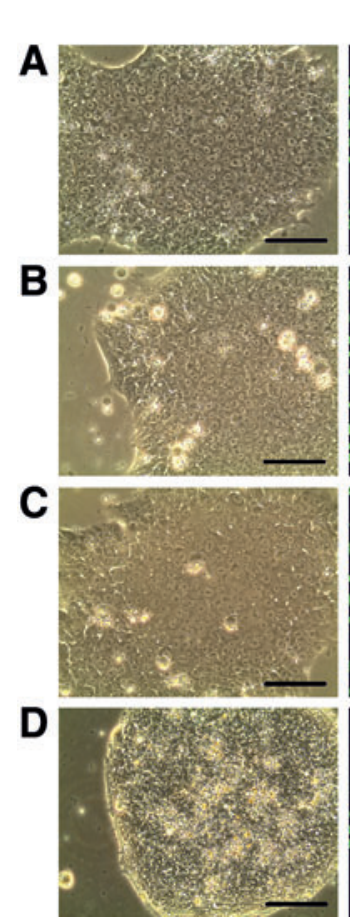

Nuclei
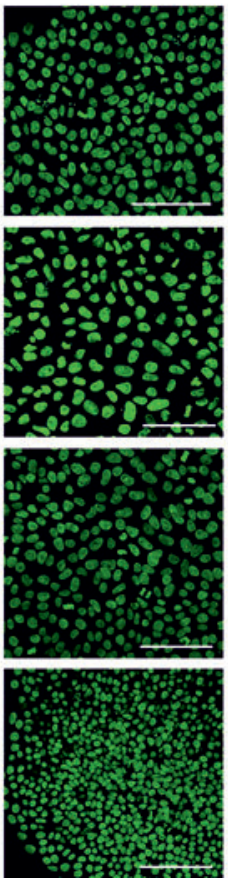

OCT4
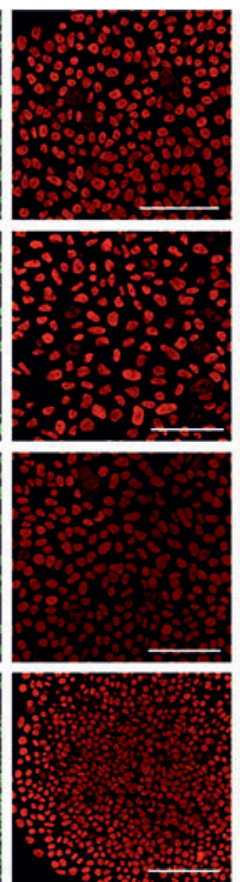

Nuclei
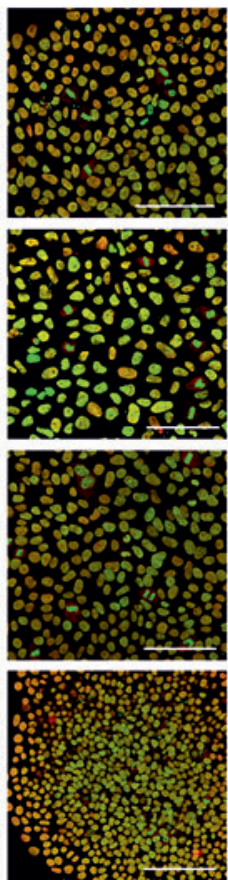

SSEA-4
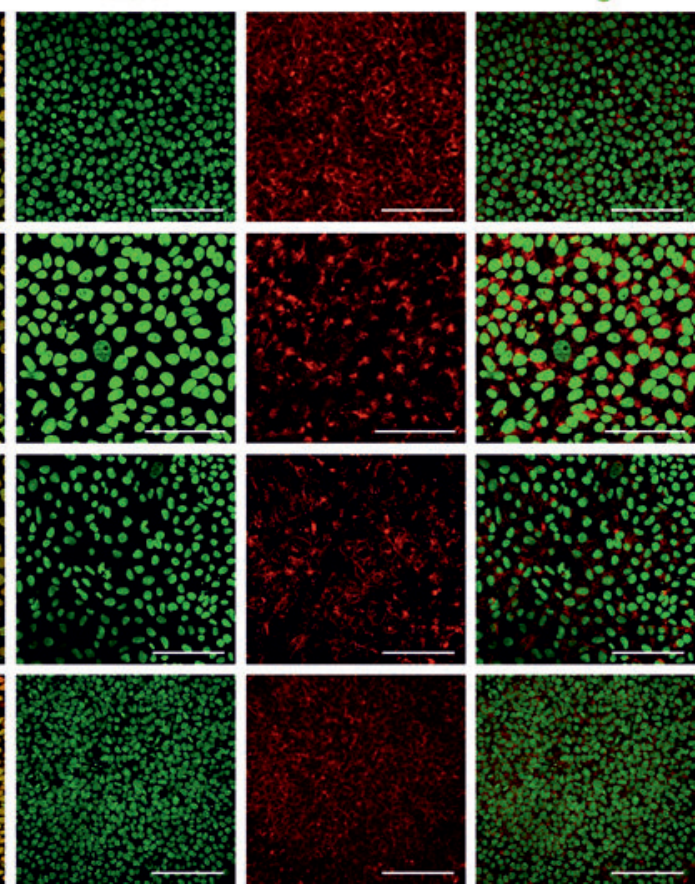

FIG. 6. Transfer of iPS(IMR90)-4 3D spheroids to 2D platforms. iPS(IMR90)-4 cells were first cultured in 0.5\% NFC hydrogel for 12 days and then transferred to $2 \mathrm{D}$ platforms after a 24 -h-treatment with $300 \mu \mathrm{g}$ cellulase $/ \mathrm{mg}$ cellulose at $37^{\circ} \mathrm{C}$. The cells exhibited typical hPSC morphology and expressed the pluripotency markers OCT4 and SSEA-4 on Matrigel-coated dishes (A), LN-511-coated dishes (B), LN-521-coated dishes (C), and VN-coated dishes (D). Scale bars, $100 \mu \mathrm{m}$. Color images available online at www.liebertpub.com/scd 

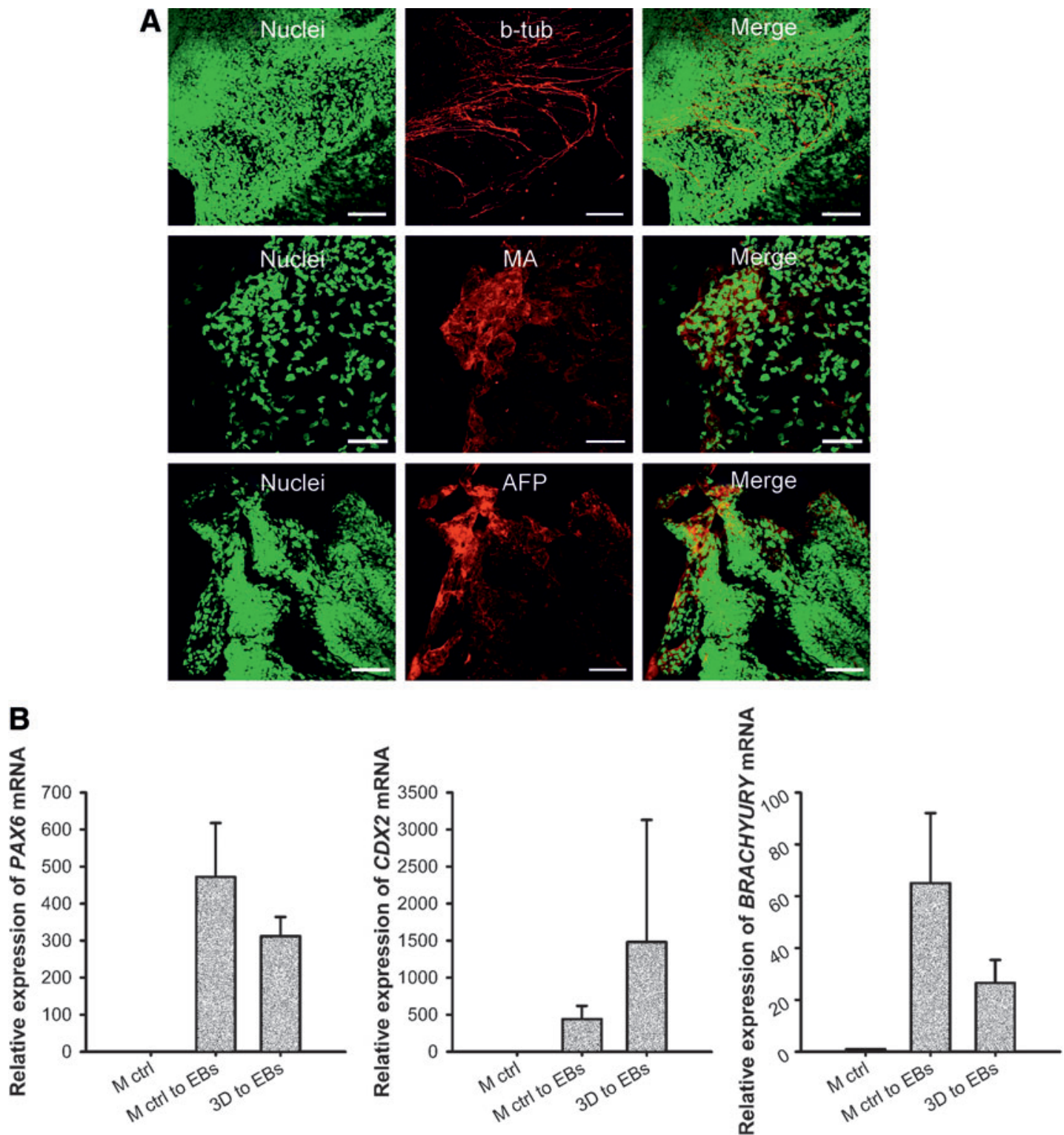

FIG. 7. In vitro differentiation of iPS(IMR90)-4 cells. (A) Embryoid bodies (EBs) were derived from iPS(IMR90)-4 cells that had previously been cultured in $0.5 \%$ NFC hydrogel for 8 days followed by a 24-h-treatment with $300 \mu \mathrm{g}$ cellulase/mg cellulose at $37^{\circ} \mathrm{C}$. Cells dissociated from 1-week-old EBs were cultured on gelatin-coated dishes for 1 week and were then detected to express three germ layer markers, $\beta$-tubulin type III (b-tub), muscle actin (MA), and $\alpha$-fetoprotein $(A F P)$. Scale bars $=100 \mu \mathrm{m}$. (B) Realtime quantitative RT-PCR analyses of PAX6, CDX2, and BRACHYURY mRNA expression in 4-week-old EBs derived from iPS(IMR90)- 4 cells that had previously been cultured in $0.5 \mathrm{wt}$. $\%$ NFC hydrogel for 9 days. Relative mRNA expression was normalized to the control gene RPLPO, and fold inductions were calculated with reference to the cells cultured on the standard Matrigel platform (M ctrl). $n=3$ biological samples. Error bars are SD. Color images available online at www.liebertpub.com/scd

and those formed indirectly after a $3 \mathrm{D}$ to $2 \mathrm{D}$ shift. Immunofluorescence in the older EBs shows strong staining of muscle actin, $H N F 3 B$, and $\beta$-tubulin type III (Supplementary Fig. S6D-F).

The teratoma formation from WA07 cells after a 26-day culture in the NFC hydrogel provides more solid evidence, showing that the 3D culture of hPSCs in the hydrogel does not alter the pluripotency of hPSCs. We observed the three germ layer derivatives in hematoxylin and eosin staining of 6-week-old teratoma sections (Fig. 8A-J). Immunofluorescence in the teratoma sections shows strong staining of $\beta$-tubulin type III and muscle actin (Supplementary Fig.
S7). The mRNA expression of $P A X 6, C D X 2$, and $B R A C H Y$ URY was dramatically increased in teratoma samples compared with cells on the standard Matrigel platform (M ctrl) (Fig. 8K).

Chromosomal G-band analyses show that after being cultured in the NFC hydrogel, WA07 and iPS(IMR90)-4 cells had normal karyotypes (Fig. 9).

\section{Discussion}

The natural stem cell niche is a dynamic 3D environment that transiently supports stem cell proliferation and is subject 

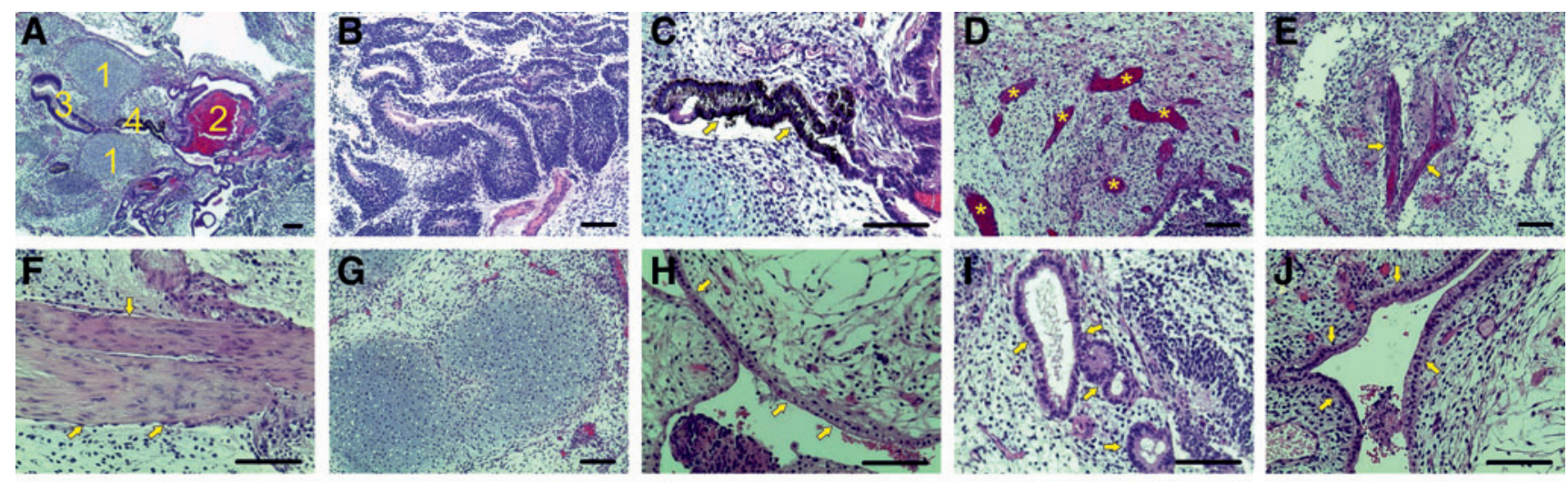

K

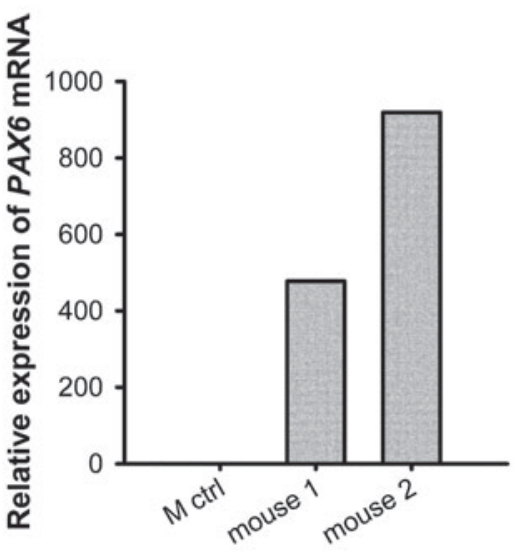

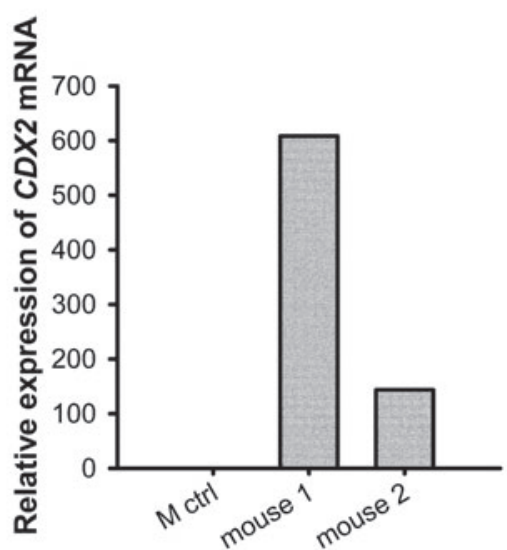

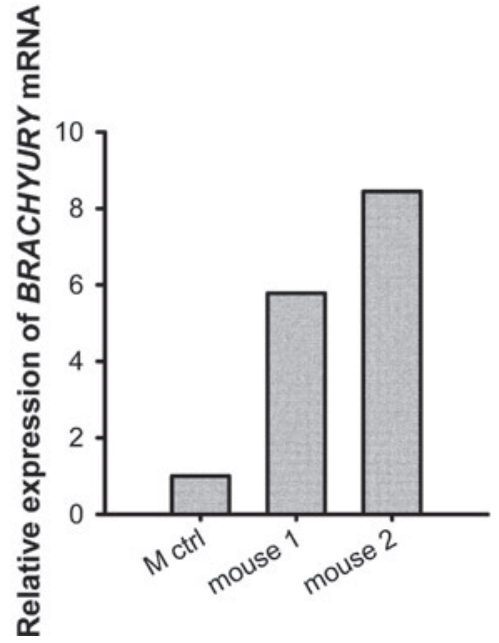

FIG. 8. In vivo differentiation of WA07 cells. (A-J) Hematoxylin and eosin staining of 6-week-old teratoma sections (5 $\mu \mathrm{m})$ of WA07 cells that had previously been cultured in 0.5 wt.\% NFC hydrogel for 26 days. (A) Cartilage (1), bone (2), epithelial tissue (3), and pigmented cells (4). (B) Neuronal rosettes (ectoderm). (C) Pigmented cells (ectoderm). (D) Blood vessels (indicated by asterisks, mesoderm). (E, F) Muscle (indicated by arrows, mesoderm). (G) Cartilage (mesoderm). (H-J) Endodermal epithelia (indicated by arrows). Scale bars $=100 \mu \mathrm{m}$. (K) Real-time quantitative RT-PCR analyses of PAX6, CDX2, and BRACHYURY mRNA expression in 6-week-old teratoma formed from WA07 cells that had previously been cultured in 0.5 wt. \% NFC hydrogel for 26 days. Relative mRNA expression was normalized to the control gene RPLP0, and fold inductions were calculated with reference to the cells cultured on the standard Matrigel platform (M ctrl). Color images available online at www.liebertpub.com/scd

A

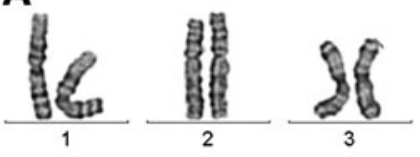

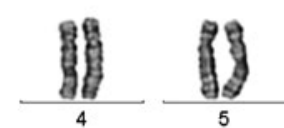

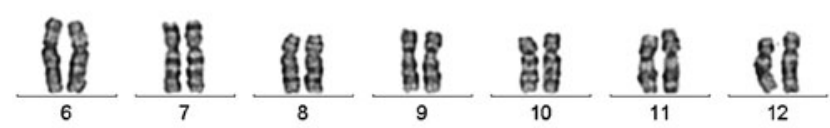

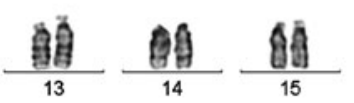

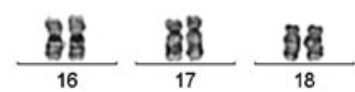

$\frac{88}{19} \frac{88}{20}$
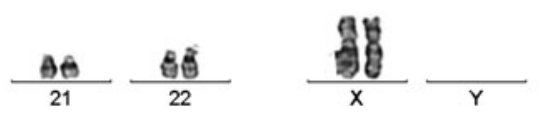
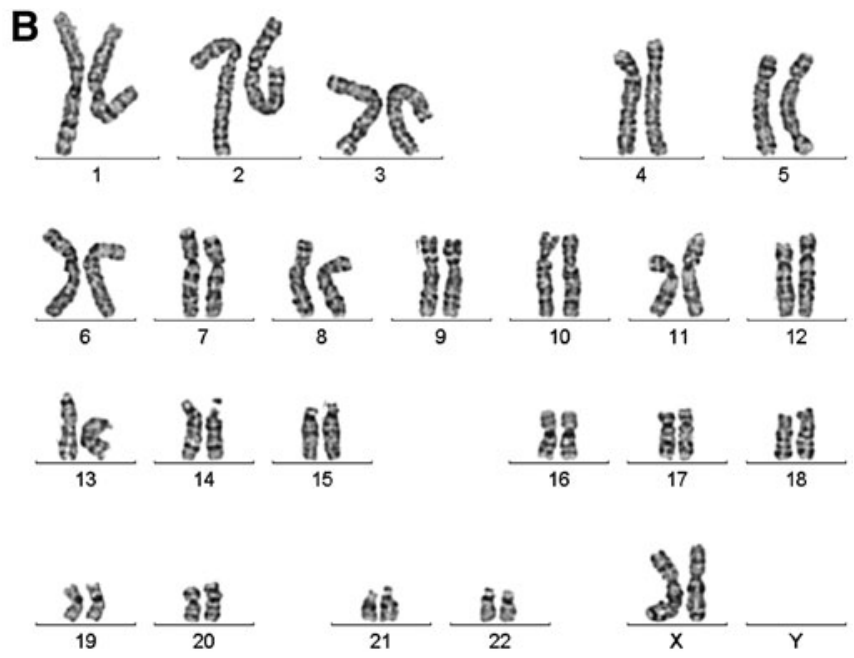

FIG. 9. The karyotypes of human ESCs and iPSCs. WA07 and iPS(IMR90)-4 cells were first cultured in $0.5 \%$ NFC hydrogel and then transferred to Matrigel-coated dishes after a 24-h treatment with $300 \mu \mathrm{g}$ cellulase/mg cellulose at $37^{\circ} \mathrm{C}$. G-banding chromosome analysis showed normal chromosomes in WA07, p41 (A) and iPS(IMR90)-4, and p18+45(20) (B) cells. 
to changes which facilitate subsequent differentiation during development. Here, we propose a new concept of hPSC culture, which is a flexible, xeno-free $3 \mathrm{D}$ in vitro culture system. This system is based on a novel plant-derived NFC hydrogel. Unlike most polysaccharide-based hydrogels that require a separate cross-linking step to form the hydrogel networks [32], the NFC forms colloidal dispersions and hydrogels in aqueous medium [33]. Thus, the hydrogels generated by cross-linking have fixed physical properties, whereas the physical property of the NFC hydrogel is dependent on its concentration, not on the degree of crosslinking. In addition, enzymatic removal of the NFC hydrogel does not affect the cells. All these features make the NFC hydrogel a flexible 3D environment.

We demonstrate that the pluripotency of hPSCs is maintained in the NFC hydrogel for 26 days. The NFC hydrogel promotes cell-cell associations into 3D spheroids with the expression of the pluripotency markers. This 3D culture can be easily shifted to 2D platforms, enabling various downstream applications. Since enzymatic removal of the hydrogel does not affect 3D cell organization, the established 3D hPSC spheroids are ready for directed differentiation into various types of cells and even $3 \mathrm{D}$ tissues, as shown in EB formation by the direct method.

We previously showed that the mechanical property (eg, viscoelasticity) of the NFC hydrogel is controllable and dependent on the NFC concentration [22]. The lower the NFC concentration is, the lower the viscoelasticity of the hydrogel is. In this study, we show that hPSCs form 3D spheroids in 0.5 wt. $\%$ NFC hydrogel, but not in $1 \mathrm{wt} . \%$ NFC hydrogel. This indicates that the lower concentration of the NFC hydrogel with less viscoelasticity is preferable for 3D hPSC spheroid formation. The mechanical properties of the human inner cell mass at the blastocyst stage are not known. An early study showed that soft substrates with elastic Young's modulus of $0.6 \mathrm{kPa}$ promote selfrenewal and pluripotency of mouse ESCs [34]. Since no cross-linking is involved in the formation of the NFC hydrogel, the mechanical property of the hydrogel can be adjusted by its concentration for subsequent differentiation steps.

To our knowledge, this is the first study using LN-521 coating in hPSC culture and also the first comparison between Matrigel coating, LN-511 coating, LN-521 coating, and VN coating in hPSC culture. It is interesting to notice that the expression of OCT4 mRNA was not well maintained in hiPSCs cultured on LN-511, LN-521, and VN coatings (Fig. 4A). VN had not been demonstrated in hiPSC culture in the previous study [6]. The expression of OCT4 mRNA in hiPSCs cultured on LN-511 coating was not demonstrated in the earlier study [7]. Nonetheless, Matrigel coating seems to be the best to maintain high levels of NANOG and OCT4 mRNA expression, although there is a cell type-dependent variation.

Earlier studies show that the pluripotency of hPSCs requires well-established cell-cell contact, which is mainly via E-cadherin [35-37]. On the other hand, cell-matrix interaction seems not to be a prerequisite as evidenced by the successful use of poor cell-adhesive hyaluronic acid hydrogel [14], alginate [15,17], and the NFC hydrogel of the current study in hPSC culture. The non-adhesive feature of the NFC hydrogel is the driving force for the for- mation of 3D spheroids. Contrary to 3D culture, cellmatrix interaction mediated by integrins seems to be important for hPSC survival and self-renewal in 2D cultures $[4,6,38,39]$.

\section{Conclusions}

This study provides a new concept of using a flexible, xeno-free 3D culture system for pluripotency of hPSCs and opens up a new avenue for better recapitulation of the natural ESC environment and embryonic development, which 2D cultures and conventional cross-linked 3D hydrogels and scaffolds could not attain.

\section{Acknowledgments}

The authors would like to thank the Academy of Finland and UPM-Kymmene Corporation for the financial support received. This research belongs to the "Biocenter Finland platform" project. The authors also want to thank Leena Pietilä and Timo Oksanen for reagent purchasing and Erja Piitulainen for laboratory logistics.

\section{Author Disclosure Statement}

No competing financial interests exist.

\section{References}

1. Thomson JA, J Itskovitz-Eldor, SS Shapiro, MA Waknitz, JJ Swiergiel, VS Marshall and JM Jones. (1998). Embryonic stem cell lines derived from human blastocysts. Science 282: 1145-1147.

2. Takahashi K, K Tanabe, M Ohnuki, M Narita, T Ichisaka, K Tomoda and S Yamanaka. (2007). Induction of pluripotent stem cells from adult human fibroblasts by defined factors. Cell 131:861-872.

3. Yu J, MA Vodyanik, K Smuga-Otto, J Antosiewicz-Bourget, JL Frane, S Tian, J Nie, GA Jonsdottir, V Ruotti, et al. (2007). Induced pluripotent stem cell lines derived from human somatic cells. Science 318:1917-1920.

4. Xu C, MS Inokuma, J Denham, K Golds, P Kundu, JD Gold and MK Carpenter. (2001). Feeder-free growth of undifferentiated human embryonic stem cells. Nat Biotechnol 19: 971-974.

5. Ludwig TE, ME Levenstein, JM Jones, WT Berggren, ER Mitchen, JL Frane, LJ Crandall, CA Daigh, KR Conard, et al. (2006). Derivation of human embryonic stem cells in defined conditions. Nat Biotechnol 24:185-187.

6. Braam SR, L Zeinstra, S Litjens, D Ward-van Oostwaard, S van den Brink, L van Laake, F Lebrin, $\mathrm{P}$ Kats, R Hochstenbach, et al. (2008). Recombinant vitronectin is a functionally defined substrate that supports human embryonic stem cell self-renewal via alphavbeta5 integrin. Stem Cells 26:2257-2265.

7. Rodin S, A Domogatskaya, S Strom, EM Hansson, KR Chien, J Inzunza, O Hovatta and K Tryggvason. (2010). Long-term self-renewal of human pluripotent stem cells on human recombinant laminin-511. Nat Biotechnol 28:611615.

8. Melkoumian Z, JL Weber, DM Weber, AG Fadeev, Y Zhou, P Dolley-Sonneville, J Yang, L Qiu, CA Priest, et al. (2010). Synthetic peptide-acrylate surfaces for long-term self- 
renewal and cardiomyocyte differentiation of human embryonic stem cells. Nat Biotechnol 28:606-610.

9. Derda R, S Musah, BP Orner, JR Klim, L Li and LL Kiessling. (2010). High-throughput discovery of synthetic surfaces that support proliferation of pluripotent cells. J Am Chem Soc 132:1289-1295.

10. Villa-Diaz LG, H Nandivada, J Ding, NC Nogueirade-Souza, PH Krebsbach, KS O'Shea, J Lahann and GD Smith. (2010). Synthetic polymer coatings for long-term growth of human embryonic stem cells. Nat Biotechnol 28: 581-583.

11. Brafman DA, CW Chang, A Fernandez, K Willert, S Varghese and S Chien. (2010). Long-term human pluripotent stem cell self-renewal on synthetic polymer surfaces. Biomaterials 31:9135-9144.

12. Irwin EF, R Gupta, DC Dashti and KE Healy. (2011). Engineered polymer-media interfaces for the long-term selfrenewal of human embryonic stem cells. Biomaterials 32: 6912-6919.

13. Kraehenbuehl TP, R Langer and LS Ferreira. (2011). Threedimensional biomaterials for the study of human pluripotent stem cells. Nat Methods 8:731-736.

14. Gerecht S, JA Burdick, LS Ferreira, SA Townsend, R Langer and G Vunjak-Novakovic. (2007). Hyaluronic acid hydrogel for controlled self-renewal and differentiation of human embryonic stem cells. Proc Natl Acad Sci U S A 104:1129811303.

15. Siti-Ismail N, AE Bishop, JM Polak and A Mantalaris. (2008). The benefit of human embryonic stem cell encapsulation for prolonged feeder-free maintenance. Biomaterials 29:39463952.

16. Li Z, M Leung, $\mathrm{R}$ Hopper, $\mathrm{R}$ Ellenbogen and $\mathrm{M}$ Zhang. (2010). Feeder-free self-renewal of human embryonic stem cells in 3D porous natural polymer scaffolds. Biomaterials 31:404-412.

17. Lu HF, K Narayanan, SX Lim, S Gao, MF Leong and AC Wan. (2012). A 3D microfibrous scaffold for long-term human pluripotent stem cell self-renewal under chemically defined conditions. Biomaterials 33:2419-2430.

18. Olmer R, A Haase, S Merkert, W Cui, J Palecek, C Ran, A Kirschning, T Scheper, S Glage, et al. (2010). Long term expansion of undifferentiated human iPS and ES cells in suspension culture using a defined medium. Stem Cell Res 5:51-64.

19. Singh H, P Mok, T Balakrishnan, $S N$ Rahmat and $R$ Zweigerdt. (2010). Up-scaling single cell-inoculated suspension culture of human embryonic stem cells. Stem Cell Res 4:165-179.

20. Steiner D, H Khaner, M Cohen, S Even-Ram, Y Gil, P Itsykson, T Turetsky, M Idelson, E Aizenman, et al. (2010). Derivation, propagation and controlled differentiation of human embryonic stem cells in suspension. Nat Biotechnol 28:361-364.

21. Amit M, J Chebath, V Margulets, I Laevsky, Y Miropolsky, K Shariki, M Peri, I Blais, G Slutsky, M Revel and J ItskovitzEldor. (2010). Suspension culture of undifferentiated human embryonic and induced pluripotent stem cells. Stem Cell Rev 6:248-259.

22. Bhattacharya M, MM Malinen, $P$ Lauren, YR Lou, SW Kuisma, L Kanninen, M Lille, A Corlu, C Guguen-Guillouzo, et al. (2012). Nanofibrillar cellulose hydrogel promotes three-dimensional liver cell culture. J Control Release 164: 291-298.
23. Walther A, JV Timonen, I Diez, A Laukkanen and O Ikkala. (2011). Multifunctional high-performance biofibers based on wet-extrusion of renewable native cellulose nanofibrils. Adv Mater 23:2924-2928.

24. Pahimanolis N, U Hippi, LS Johansson, T Saarinen, N Houbenov, J Ruokolainen and J Seppala. (2011). Surface functionalization of nanofibrillated cellulose using clickchemistry approach in aqueous media. Cellulose 18:12011212.

25. Filpponen I, E Kontturi, S Nummelin, H Rosilo, E Kolehmainen, O Ikkala and J Laine. (2012). Generic method for modular surface modification of cellulosic materials in aqueous medium by sequential "click" reaction and adsorption. Biomacromolecules 13:736-742.

26. Vartiainen J, T Pohler, K Sirola, L Pylkkanen, H Alenius, J Hokkinen, U Tapper, P Lahtinen, A Kapanen, et al. (2011). Health and environmental safety aspects of friction grinding and spray drying of microfibrillated cellulose. Cellulose 18:775-786.

27. Borges AC, C Eyholzer, F Duc, PE Bourban, P Tingaut, T Zimmermann, DP Pioletti and JA Manson. (2011). Nanofibrillated cellulose composite hydrogel for the replacement of the nucleus pulposus. Acta Biomater 7: 3412-3421.

28. Klemm D, F Kramer, S Moritz, T Lindstrom, M Ankerfors, D Gray and A Dorris. (2011). Nanocelluloses: a new family of nature-based materials. Angew Chem Int Ed Engl 50: $5438-5466$.

29. Mathew AP, K Oksman, D Pierron and MF Harmand. (2013). Biocompatible fibrous networks of cellulose nanofibres and collagen crosslinked using genipin: potential as artificial ligament/tendons. Macromol Biosci 13: 289-298.

30. Suurnakki A, M Tenkanen, M Siika-Aho, ML Niku-Paavola, L Viikari and J Buchert. (2000). Trichoderma reesei cellulases and their core domains in the hydrolysis and modification of chemical pulp. Cellulose 7:189-209.

31. Tenkanen M, J Puls and K Poutanen. (1992). 2 Major xylanases of Trichoderma-reesei. Enzyme Microb Technol 14:566574.

32. Cheng Y, XL Luo, GF Payne and GW Rubloff. (2012). Biofabrication: programmable assembly of polysaccharide hydrogels in microfluidics as biocompatible scaffolds. J Mater Chem 22:7659-7666.

33. Paakko M, M Ankerfors, $H$ Kosonen, A Nykanen, $S$ Ahola, M Osterberg, J Ruokolainen, J Laine, PT Larsson, O Ikkala and T Lindstrom. (2007). Enzymatic hydrolysis combined with mechanical shearing and high-pressure homogenization for nanoscale cellulose fibrils and strong gels. Biomacromolecules 8:1934-1941.

34. Chowdhury F, Y Li, YC Poh, T Yokohama-Tamaki, N Wang and TS Tanaka. (2010). Soft substrates promote homogeneous self-renewal of embryonic stem cells via downregulating cell-matrix tractions. PLoS One 5:e15655.

35. Xu Y, X Zhu, HS Hahm, W Wei, E Hao, A Hayek and S Ding. (2010). Revealing a core signaling regulatory mechanism for pluripotent stem cell survival and self-renewal by small molecules. Proc Natl Acad Sci U S A 107:81298134.

36. Li L, SA Bennett and L Wang. (2012). Role of E-cadherin and other cell adhesion molecules in survival and differentiation of human pluripotent stem cells. Cell Adh Migr 6:59-70. 
37. Watanabe K, M Ueno, D Kamiya, A Nishiyama, M Matsumura, T Wataya, JB Takahashi, S Nishikawa, K Muguruma and Y Sasai. (2007). A ROCK inhibitor permits survival of dissociated human embryonic stem cells. Nat Biotechnol 25: 681-686.

38. Mei Y, K Saha, SR Bogatyrev, J Yang, AL Hook, ZI Kalcioglu, SW Cho, M Mitalipova, N Pyzocha, et al. (2010). Combinatorial development of biomaterials for clonal growth of human pluripotent stem cells. Nat Mater 9:768-778.

39. Meng Y, S Eshghi, YJ Li, R Schmidt, DV Schaffer and KE Healy. (2010). Characterization of integrin engagement during defined human embryonic stem cell culture. FASEB J 24:1056-1065.
Address correspondence to:

Dr. Yan-Ru Lou

Division of Biopharmaceutics and Pharmacokinetics Faculty of Pharmacy University of Helsinki Helsinki 00014 Finland

E-mail: yan-ru.lou@helsinki.fi

Received for publication July 14, 2013 Accepted after revision September 30, 2013 Prepublished on Liebert Instant Online November 4, 2013 